\title{
OCEAN MONITORING AND FORECASTING CORE SERVICES, THE EUROPEAN MYOCEAN EXAMPLE
}

\author{
Pierre Bahurel $^{(1)}$, Frédéric Adragna ${ }^{(2)}$, Mike J. Bell ${ }^{(3)}$, Fabienne Jacq ${ }^{(4)}$, Johnny A. Johannessen ${ }^{(5)}$, \\ Pierre-Yves Le Traon ${ }^{(6)}$, Nadia Pinardi ${ }^{(7)}$, Jun She ${ }^{(8)}$ \\ ${ }^{(1)}$ Mercator Océan, 8-10 rue Hermès, Ramonville Saint Agne, France, Pierre.Bahurel@ mercator-ocean.fr \\ ${ }^{(2)}$ Mercator Océan, 8-10 rue Hermès, Ramonville Saint Agne, France, Frederic.Adragna@mercator-ocean.fr \\ ${ }^{(3)}$ Met Office, FitzRoy Road, Exeter, Devon EX1 3PB, United Kingdom, Mike.Bell@metoffice.gov.uk \\ ${ }^{(4)}$ CLS, 8-10 rue Hermès, Ramonville Saint Agne, France, Fabienne.Jacq@cls.fr \\ ${ }^{(5)}$ NERSC, Thormøhlensgt, 47N-5006 Bergen, Norway, Johnny.Johannessen@nersc.no \\ ${ }^{(6)}$ IFREMER, Centre de Brest, B.P. 70. 29280 Plouzané, France, Pierre.Yves.Le.Traon@ifremer.fr \\ (7) INGV, Via Donato Creti, 12, I-40100 Bologna, Italy, n.pinardi@sincem.unibo.it \\ ${ }^{(8)}$ DMI, Centre for Ocean and Ice, Lyngbyvej 100, DK-2100, Copenhagen, Denmark, js@dmi.dk
}

\begin{abstract}
Since OceanObs 1999, ocean monitoring and forecasting core services have reached an initial level of maturity. A world-wide network of operational oceanography centres now provide real-time information on the ocean based on space and in situ observations and assimilative models.

Europe has defined in 2005 the "Marine Core Service" as a new pan-European service aiming at delivering to anyone, and particularly downstream service providers, core information on the ocean (currents, temperature, sea surface height, ice coverage and thickness, primary ecosystems,...) recognized as common denominator data required to develop adding-value services.
\end{abstract}

MyOcean is the first implementation project of this integrated pan-European Marine Core Service for ocean monitoring and forecasting. This 3-year project started in 2009 and involves 61 partners in 29 countries.

MyOcean users are service providers involved in four application areas: marine safety, marine resources, marine and coastal environment and weather, seasonal and climate prediction. They form a wide and diverse community but share a common interest for a generic information on the ocean state as an input to their own services.

MyOcean has already opened a first marine core service for ocean monitoring and forecasting, and provides access to a range of observation-based and model-based products. This is based on a "system of systems" organization interconnecting different centres in Europe to form a single pan-European capacity with five thematic assembly centres dealing with observations, seven monitoring and forecasting centres dealing with assimilative models and a single service desk to ensure the easiest access to users. This operational oceanography service relies on remote-sensed and in situ observation networks and their sustainability.
What are the main choices we've made in Europe to define MyOcean? The market, the service offer, the production capacity and the organization that will drive the implementation of a Marine Core Service in Europe? What is required upstream from observation networks to run such a service? What is required downstream from this service by operational oceanography users to develop further their mission?

\section{OCEAN MONITORING AND FORECASTING CORE SERVICES, INTRODUCTION}

Ocean forecasts are provided on a regular basis by more than a dozen operational oceanography centres in the world. Forecasts are produced by routine assimilation of real-time remotely sensed and in situ data into numerical models. Some of them describe the global ocean as a whole, others are regional.

Europe, Australia, the United States, Canada, Japan, and now China, are deeply engaged in the development and consolidation of an operational ocean monitoring and forecasting capacity. Space oceanography programs, as well as in situ ones (e.g. the international Argo program (Global array of free-drifting profiling floats)), are gathering a wider range of countries in this global earth observation challenge for the ocean; this large international cooperative effort is actively coordinated through GOOS (Global Ocean Observing System) and GEOSS (Global Earth Observation System of Systems).

Systems such as Mercator (France), FOAM (Forecasting Ocean Assimilation Model) (UK), TOPAZ (Towards an Operational Prediction system for the North Atlantic European coastal Zones) (Norway) and MFS (Mediterranean Ocean Forecasting System) (Italy) in Europe, and BLUElink (Ocean forecasting Australia) in Australia, HYCOM (Hybrid Coordinate Ocean Model) and ECCO (Estimating the Circulation \& Climate of the Ocean) in the United States, Concepts in Canada, and the systems run at JMA/MRI/JMASTEC in (Japan Meteorological Agency/Meteorological Research 
Institute/ Japan Agency for Marine-Earth Science and Technology) Japan, and SOA/NMEFC (State Ocean Administration/National Marine Environmental Forecasting Center) in China are today international references for ocean monitoring and forecasting core services. The GODAE (Global Ocean Data Assimilation Experiment) Ocean View international initiative (see [2] and http://www.godae.org) provides up-to-date references of existing monitoring and forecasting systems at the international level.

\section{THE EUROPEAN MARINE CORE SERVICE AND THE MYOCEAN PROJECT}

Europe acknowledged quite early the need and opportunity for a global ocean monitoring and forecasting capacity, and took structuring initiatives to make it happen. Leading European countries such as France, the United Kingdom, Norway and Italy have been involved in international coordination for more than a decade to foster development of new systems, services and skilled teams in marine core services. The GMES MERSEA (Global Monitoring for Environment and Security/Marine Environment and Security for the European Area) projects (from 2003 to 2008; see [4], [5] and [6]) made a real difference at the EU level to start the integration of the different ocean monitoring and forecasting production national facilities in one panEuropean approach, and gave to Europe a new and valuable focal point for international coordination.

In October 2005, the European Commission held a workshop devoted to the marine component of the GMES program, which defined the "Marine Core Service" (MCS) and took actions for its implementation. The MCS Implementation Group, set up by the Commission to supervise and validate the implementation of this new Service, proposed this definition (see [8]): "The MCS is conceived as one part of a processing chain which operates on observational and other forms of data to help create tailored information services to meet a wide range of end user needs. Almost all such end user services relating to the marine environment require access to information about the state and dynamics of the oceans and seas. The MCS provides that information to intermediate users who combine it with other forms of information and data (e.g. socio-economic data) to provide customized downstream services for the end users. The implementation of the overall chain needs to have some flexibility; as components of downstream services are developed to serve multiple uses, it may be more efficient for them to be provided as part of the MCS". Figure 1 illustrates this segmentation of the valueadding chain, and the role taken by the "core" service in this chain.

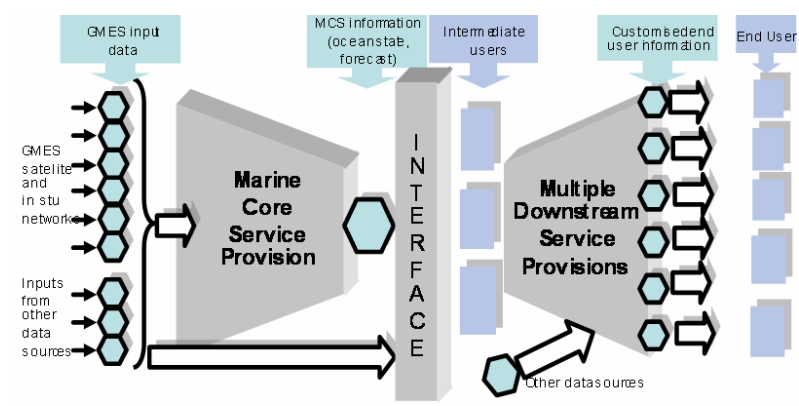

Figure 1: The GMES value-adding chain for the marine information services, positioning the Marine Core Service

The Marine Core Service GMES program provides a multi-year framework to develop in Europe the expected ocean monitoring and forecasting capacity.

MyOcean (see [1]) is the first implementation project of this initiative. Co-funded by the European Commission under the 7th Framework Program (FP7), MyOcean covers the 3 year period 2009-2010-2011 with a total cost of $55 \mathrm{M} €$, of which $60 \%$ (34 M€) are funded by the European Commission. MyOcean has to deliver a service, its assessment and an overall organization driven by user's needs.

As a marine core service, the MyOcean objective is to provide to users the best generic information available on the state of the ocean. MyOcean is committed to develop and run a pan-European service based on a worldwide capacity for ocean monitoring and forecasting, using data assembly, modelling and assimilation systems. The service is intended to serve any users requesting generic information on the ocean, and especially downstream service providers who will use this information as an input to their value-added services to end-users. These "intermediate users" cover a wide range of downstream sectors of the marine field itself but also connected fields (e.g. climate, living resources, etc.). The MyOcean service consists in providing "core" information on the ocean, defined as the common denominator data requested by these service providers for their different and specific sector. It corresponds to the main variables needed to depict the ocean state: temperature, salinity, currents, sea level, ice coverage and thickness, primary ecosystem variables, etc. MyOcean provides this information for the daily state of the ocean (real-time), its short-term evolution (forecast for the days coming, up to 10-14 days), and its history over the past 20-50 years (hindcast and reanalysis). Users access the information through a centralized service desk.

As a European team, MyOcean gathers 61 partners spread over 29 different countries. It means a team of around 350 people with 29 different nationalities, gathered by a common objective. All maritime nations of the European Union are represented in MyOcean, and 
the team welcomes as well some non-European associate nations. The project gathers in this large team a large variety of skills and experience - research and development, operations and service, technical and industrial development, user applications, quality assessment and management - to contribute to the project activity. Each partner has been assigned a specific role to play. A group of around 20 "core partners" is committed to implement and provide the MyOcean service. They are playing a key role; European best players in operational ocean monitoring and forecasting are involved and committed. Another third of the consortium ( 20 partners) provides the scientific and industrial support needed for the quality control of the implementation, and the last third $(\sim 20$ partners) forms a network in Europe devoted to set up and develop links with the user community.

The MyOcean objectives and the composition of the consortium can be found on http://www.myocean.eu

\section{MYOCEAN USERS REQUIREMENTS}

The MyOcean market consists of "intermediate users": service providers serving specific end-users who need core information about the ocean as an input to their activities.

Users of MyOcean are the service providers requiring core information on the ocean to run their activities: they are called intermediate users since they are the mandatory intermediates between the core service and the end-users. They have different status, running operational or research activities, in the marine sector but opened to a wide variety of application areas. They include national public agencies, such as national weather services and marine institutes, European agencies such as the European Environmental Agency and the European Maritime Safety Agency, private companies providing services on a specific market niche, research laboratories, and environment policy conventions (e.g. HELCOM (Helsinki Commission), OSPAR (Oslo and Paris Conventions for the protection of the marine environment of the North-East Atlantic), UNEP/MAP (United Nations Environment Programme/ Mediterranean Action Plan). They have in common that they are in direct contact with the end-users, and that they need upstream core information on the ocean. MyOcean has invited a number of intermediate users to join the project to foster the service and market development. Users of the MyOcean service are adding value to the core ocean information to meet their own end-users needs.

MyOcean has segmented the market into four areas to cover the whole spectrum of requirements and structure the marine core service offer and has built a network to manage the user requirements. The four market areas help define the core service required by coherent groups of users. These four areas of benefit are: (i) the "marine safety" area; (ii) the "marine resources" area; (iii) the "marine and coastal environment" area, and (iv) the "weather, seasonal and climate prediction" area.

MyOcean is organized to capture and manage users' requirements throughout the project, to specify service evolution. A network of reference users in Europe has been organized amongst the 60 partners of the project to cover the European territory (Fig. 2).

This network is tasked to link with the main users of the four market areas, and to organise and feed the users' requirement reference documentation. A core user group, composed of a small selection of users, serves as an advisory group for the project coordination (see below).

Users' requirements captured by the MyOcean organization and partners' experience are presented below. They will be enriched all along the project.

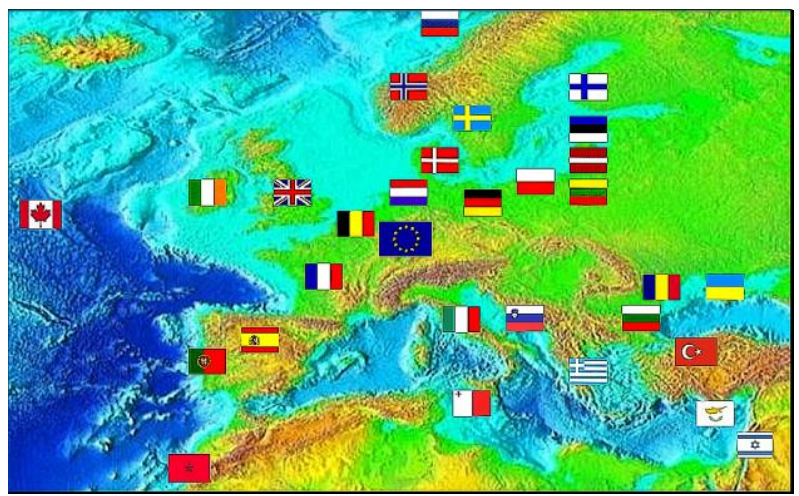

Figure 2: MyOcean network of reference intermediate users involved in the project, spread in 29 countries

The general requirement is to get access, on a systematic and guaranteed basis, to reliable and synthetic information on the physical and biogeochemical state of the ocean, based on the combination or assimilation into $3 \mathrm{D}$ ocean general circulation models of remote-sensed and in situ observations. Variables expected are for the physical part: sea level, sea surface height, temperature, salinity, currents, surface wind and waves, sea ice (extent, concentration, thickness, motion) and for the biophysical and biogeochemical part: attenuation of solar radiation, chlorophyll, dissolved inorganic matter $(\mathrm{O} 2, \mathrm{pCO} 2, \ldots)$, dissolved nutrients and primary production. It is required a global ocean coverage with a focus on European seas, and a capacity to solve mesoscale dynamics as well as to provide reliable information for multi-year global trends. Real-time information is required (operational monitoring and forecasting) as well as multi-decadal reanalyses of ocean state. Users express also requirements to receive a fully assessed information and indication on products quality. 
Segmenting the application field in four areas allows to understand better MyOcean users expectation:

- In the "marine safety" area, users are service providers involved in marine operations, oil spill combat, ship routeing, defence, search $\&$ rescue... and all marine activities requesting offshore operations. The European Maritime Safety Agency, marine meteorology of the national weather services and Navies are users in this area. Their first requirement is a "real time and operational" ocean core information (hindcast, nowcast, forecast), mainly for the surface layers of the ocean and the mesoscale circulation (eddies, fronts, ...). These users are also users of marine weather wind $\&$ waves information. They ask for systematic and routine information, with possibly rapid environment assessment request. High resolution in time and space, limited area coverage but with a worldwide capacity, are required.

- In the "marine resources" area, users are service providers involved in the evaluation and monitoring of marine resources such as fish stock management. The International Council for the Exploitation of the Sea (ICES) and national marine institutes are some of the users identified in this area. These users require information related to ocean physics and primary ecosystems, with fully assessed analyses of the present situation and long-term trends over the last 10-20 years. They require an excellent estimation of the physical state of the ocean (such as vertical speed) to enable efficient coupling with ecosystem modelling. Long-term simulations, trends and anomalies, with a global and basin-scale views to cover large marine ecosystems areas are required. Realistic monitoring at higher resolutions is expected.

- In the "marine and coastal environment" area, users are service providers involved in coastal monitoring and environmental assessment activities. The European Environmental Agency and the national environmental agencies are natural users identified here, as well as environmental policy conventions such as UNEP/MAP in the Mediterranean Sea, OSPAR in the Atlantic, HELCOM in the Baltic Sea, and any institutes or companies running coastal monitoring systems. These users require three-dimensional depictions of the ocean state and its variations, boundary conditions to force coastal monitoring systems, and reference and standard indicators on the ocean environment status. They are particularly demanding on high-resolution information when approaching the coastal areas; sea level information, remote-sensed ocean color and surface temperature, and high-resolution 3D model information are required for environmental assessment activities.

- In the "weather, seasonal and climate prediction" area, users are mainly services involved in weather forecasting, but also services monitoring polar ice extent evolution and the global environment for climate. The European Centre for Medium-range Weather Forecasting and national weather services in Europe are users in this area, as well as groups involved in international initiatives such as the International Polar Year; and any private or public entities involved in services linked to the exploitation of climate and seasonal forecasting information. These users require global ocean analyses and multi-decadal past trends with coupled ocean-ice models.

\section{THE MYOCEAN SERVICE OFFER}

MyOcean offers to users a reliable and easy access to valuable ocean core information. The MyOcean service offer is driven by quality and simplicity: quality of the ocean information provided to users, and simplicity of the access to information. Providing a clear and easy access to the ocean core information available in Europe is considered by MyOcean partners as the first priority. This is why the first investment is on the inventory of the "core products" available (the portfolio) and on the service tools and organization (the desk). In the initial definition of MyOcean, the aim to facilitate users' access to information as much as possible has been a strong driver, forcing technical \& organisational decisions (one single desk) and legal / economical decision (open and free data policy).

MyOcean delivers "regular and systematic reference information (processed data, elaborated products) on the state of the oceans and regional seas, at the resolution required by intermediate users and downstream service providers, of known quality and accuracy, for the global and European regional seas". This mission, as defined by the Marine Core Service Implementation Group of the European Commission, drives the MyOcean service definition. The information provided concerns the physical state of the ocean (temperature, salinity, currents, density, sea level, ice coverage and concentration, ...) and primary ecosystem variables at the mesoscale following users' requirements presented above. The service is provided daily all around the world by a "global ocean" component with higher resolution information for the European seas provided by "regional seas" components. The information is based on the combination of space and in situ observations and 3D ocean models with data assimilation. MyOcean offers a real-time service consisting of nowcasts (real-time analyses) and forecasts (1-2 weeks), and a reanalysis service 
describing past events and trends over the past 20-25 years. This is compliant to users' first requirements described above.

The MyOcean products are fully and openly accessible and delivered free of charge. This data policy has been deliberately designed to be as simple as possible and to simplify access to products by users. The products are made available without any restrictions on their use (e.g. commercial) other than uncontrolled redistribution or reselling without adding value. The only undertakings made by users signing the licence are to acknowledge MyOcean as the source of data and to answer enquiries aimed at assessing and improving the service. The MyOcean 3-year project is seen at European level as a full-scale demonstration of the value of this open data policy.

The MyOcean catalogue describes the list of products proposed to users by the production centres. This document is indeed the cornerstone of the service offer, and drives upstream all the production chain. The products available from MyOcean are defined in its service portfolio, which describes the products (geographical coverage, depth level, spatial \& temporal resolutions, temporal extent, and quality flag), their quality \& delivery characteristics (timeliness, format, user standards) and dissemination mode. The goal is to set up a simple and single portfolio for the whole panEuropean MyOcean marine core service, with reference definitions shared by users, producers and stakeholders, and regularly updated. 111 standard product lines are made available through this catalogue six months after the project kick-off: all geographical areas are covered by assimilative models which ensures access to monitoring and forecasting model information on the global ocean and in European regional seas; all observed variables are covered by data centres which ensures access to remote-sensed sea level, ocean color, sea surface temperature, ice, wind and in situ data. All products have been gathered and made accessible through a single "Online Queryable Catalogue", which can be accessed through http://www.myocean.eu. Every product is described by a "product-ID" where anyone can found all relevant information on content and format; interested users are then invited to reach the service desk.

MyOcean has set up a "service desk", which is a single entry point to access the product and service portfolio. This service desk consists of a secured web portal which includes a self service facility (with a user registration form and user query form) the service portfolio, access to product documentation, a visualization service, user outreach and feedback questionnaires and knowledge management resources. Email contact is ensured through: servicedesk@myocean.eu.org. The MyOcean service desk also has a service desk call centre (24/7), an operations service desk support team, an integrated
IT service desk tool, change management, access rights management and knowledge management tools. The MyOcean service provision is governed by Service Level Agreements (SLAs) with the MyOcean users. The ITIL (Information Technology Infrastructure Library) international standard for service organization has been chosen to drive the MyOcean service definition and organization.

\section{THE MYOCEAN PRODUCTION}

The MyOcean production capacity is based on a "system of systems" organization interconnecting different centres in Europe. This system-of-systems architecture has been chosen for its ability to involve the first-rank centres in Europe (to retrieve from them the best information for users) and to define a clear and demanding industrial \& service organization (to provide an operational service). The functional architecture is organised to allow operations of the Marine Core Service based on physically spread infrastructures (see Fig. 3). Functions cover all requirements in terms of production and service. Common functionalities have been federated into common sub-systems to allow interoperability, standardisation, and economy of scale.

The system functional architecture is broken down into 14 sub-systems: 12 production units and 2 central components. The production units are either "Thematic Assembly Centres (TACs)" dealing with observations or "Monitoring and Forecasting Centres (MFCs)" dealing with model \& assimilation. The 2 central components manage the information produced and provide the portal to users. They support all the TACs and MFCs, by ensuring common standards and interfaces leading to cost-effective economies of scale and the interoperability required by users. The physical architecture is spread across seven countries (Denmark, France, Italy, Norway, Spain, UK, and Ukraine), centres being linked with WIS/GTS (Wisconsin/Global Telecommunication System) network, Internet protocols and in some specific cases with EUMETCast (Broadcast system of the European Organisation for the Exploitation of Meteorological Satellites).

The 12 production units are the real pillars of the MyOcean organization; each of them has a specific mission to conduct in the overall service organization. A MyOcean 'production unit' has its own internal organization, run under the responsibility of a leading entity, but has to ensure R\&D activities to prepare the service evolution, system development and integration, service operations, and assessment of the production. Each production unit is run by a leading entity with the potential involvement of other entities and operational service commitments.

a) The Thematic Assembly Centres (TACs) are the MyOcean Production Units dealing with the 


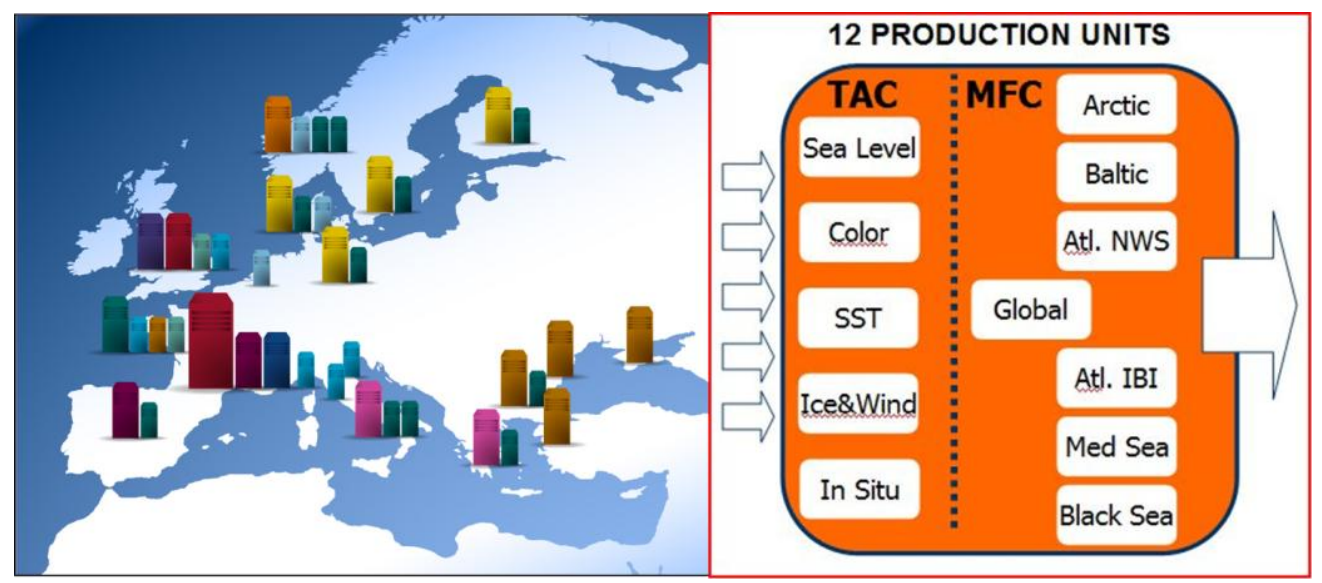

Figure 3: The MyOcean production "system of systems" composed of 12 production units

observation-based information; they are committed to provide the products based on observation data that are required by the MFCs for assimilation or validation, and the ones identified in the MyOcean products portfolio for dissemination to users. They provide hindcast (past) and nowcast (real time) information. They retrieve the observations from the observation agencies data centres with a first level of processing, and ensure the final processing and validation steps.

Five Thematic Assembly Centres are identified:

- The "Sea Level" TAC,

- The "Ocean Color" TAC,

- The "Sea Surface Temperature" TAC,

- The "Sea ice and Wind" TAC,

- The "In situ data" TAC

b) The Monitoring and Forecasting Centres (MFCs) are the MyOcean Production Units dealing with the model-based information. They are committed to provide the products based on model data identified in the MyOcean products catalogue for dissemination to users. They provide hindcast (past), nowcast (real time) and forecast (future) information. They use the information provided by the TACs, and some additional ancillary data, run assimilative models and ensure the ocean state monitoring. Seven Monitoring and Forecasting Centres are identified, one for the global ocean and six for European regional seas:

- The "Global Ocean" MFC, which deals with the whole global ocean

- The "Arctic" MFC, which deals with the Artic polar region

- The "Baltic sea" MFC, for the Baltic Sea

- The "NWS" MFC, for the North-West-Shelves region in the Eastern-North Atlantic
- The "IBI" MFC, for the Iberian-Biscay-Irish region in the Eastern-North Atlantic

- The "Mediterranean sea" MFC, for the Mediterranean sea

- The "Black Sea" MFC, for the Black sea

All in all these 12 production units (5 TACs and 7 MFCs) maintain appropriate capacities and mechanisms to ensure that the products are state of the art, and characterised and delivered to the right standards. They set up appropriate mechanisms and activities to ensure the maintenance and the long-term evolution of the committed service.

\section{OBSERVATION REQUIREMENTS}

Ocean monitoring and forecasting services are critically dependent upon remote-sensed and in situ data, either for assimilation into ocean circulation models or direct combination into databased products. As for operational oceanography in general, the main requirement for the European MyOcean Marine Core Service is to have a long-term, continuous and near real time access to the core operational observations of sea level, temperature, ocean colour, sea ice, wave and winds. Long-term continuity and transition from research to operational mode remains a major challenge. MyOcean requirements are common to international requirements as presented by GOOS and its international GODAE initiative (see for instance ref. [3] and ref. [7]).

Regarding remote-sensed data,

- in addition to meteorological satellites, a high precision (AATSR-class) (Advanced Along Track Scanning Radiometer) SST satellite is needed to give the highest absolute SST accuracy. A microwave mission is also needed to provide an all weather global coverage.

- at least 3 or 4 altimeters are required to observe the mesoscale circulation. This is also useful for 
significant wave height measurements. A long-term series of a high accuracy altimeter system (Jason satellites) is needed to serve a reference for the other missions and for the monitoring of climate signals.

- Ocean colour is increasingly important, in particular, in coastal areas. At least 2 satellites are required.

- Two scatterometers are required to globally monitor at high spatial resolution the wind field.

- Two SAR satellites are required for waves, sea-ice characteristics and oil slick monitoring.

Regarding in situ data, there is a wide consensus on the initial system to sustain both for climate and operational oceanography objectives. This in situ observation network includes:

- Argo (Array for Real-time Geostrophic Oceanography), a global array of profiling floats measuring temperature and salinity profiles as well as deep ocean currents. Argo is the primary source of data on the ocean interior. It constitutes a costeffective system for basin scale, real-time global observations in the upper $2000 \mathrm{~m}$.

- Data from ships of opportunity: XBTs for the measurement of temperature profiles down to $\sim 450$ $750 \mathrm{~m}$, sea surface temperature and salinity from TSGs.

- Surface drifters: cheap and light-weight platforms that passively follow the horizontal flow at the surface. They also provide precise sea surface temperature measurements.

- Moorings: at present the only technology to provide a complete long-term suite of physical, air/sea interaction and biogeochemical quantities, like chlorophyll, oxygen, CO2, oxygen, nutrients. These data are essential for validation and assessment purposes.

- The global Tide Gauge Network, which provides long-term reference and validation sea level data.

- Data from research vessels that deliver complete suites of multidisciplinary parameters from the surface to the ocean floor. The information collected is of high accuracy, quite necessary for various validation tasks, deep ocean and carbon observations but very sparse, with intermittent spatial coverage and at high cost of operations.

\section{THE MYOCEAN GOVERNANCE}

The MyOcean organization (see Fig. 4) is meant to transition the current organization, mainly driven by an R\&D ethos and challenges, to an organization that will preserve its innovation capacity through $R \& D$ but support a sustainable, reliable and efficient operational activity at European level. The MyOcean pan-European service organization is driven through a Board for the strategic issues, and an Executive Committee for the technical \& service management. Two advisory bodies provide support: one dealing with users' issues and the other with research and development. The work is broken down into 18 work packages, 14 of them being run as business units in charge of the 14 subcomponents of the systems (the 5 Thematic Assembly Centres, 7 Monitoring and Forecasting Centres, the management information system and the data portal).

The MyOcean Board is the acting governing body supporting the coordinator in the steering and strategic management actions and decisions. It is composed of the coordinator P. Bahurel (Mercator Océan, France), six senior scientists and managers - M. Bell (Met Office, UK), F. Jacq (CLS (Collecte, Localisation, Satellites) France), J. A. Johannessen (NERSC (Nansen Environmental and Remote Sensing Centre), Norway), P.-Y. Le Traon (IFREMER (French Research Institute for Exploration of the Sea), France), N. Pinardi (INGV (National Institute of Vulcanology and Geophysics), Italy) and J. She (DMI (Danish Meteorological Institute), Denmark). The Board has two main roles: (i) a strategic role to explore any management, strategic, legal and organizational issues that could contribute to feed the GMES Marine Core Service long term roadmap, such as agreements with external providers or major users, links with international programs and national initiatives and preparation of the next Marine Core Service management organization; (ii) a steering role, supporting the project coordinator in the project coordination and making important decisions on priorities (e.g. evaluation of progress objectives/achievements). The Board is tasked to develop and maintain international relations with other services and centres in the world. It reports to the General Assembly, which is the ultimate decisionmaking body of the consortium, composed of one institutional representative appointed by each of the 60 partners.

The MyOcean Advisory Committee, composed of highlevel representatives of GMES Stakeholders, advises the MyOcean Board. These directors of European agencies and organisations provide a strategic vision and help to align the direction of the project in full compliance with the requirements of GMES stakeholders, in order to assure the sustainability of the Marine Core Service. The Committee is co-chaired by the project coordinator and the chairperson of EuroGOOS (European Global Ocean Observing System). Two other advisory bodies are supporting the coordinator and the partners. The Core User Group consists of a dozen representatives of the User community, and provides recommendations on the service evolution, and feedback on the present situation. It supports any analysis regarding a new service line (new products, new requests ...), and helps in setting up efficient links with the user community as a whole. The Core User Group is involved in the organization of the User Forums. The Scientific 


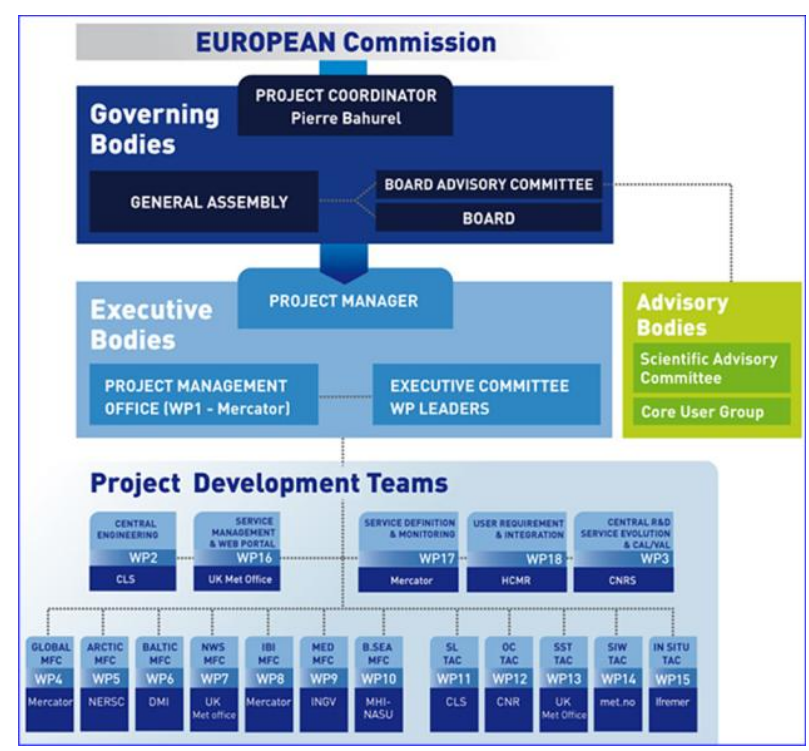

Figure 4: The MyOcean project organization

Advisory Committee is composed of senior scientists and provides support on scientific strategy. It deals with the scientific quality of the service provided and makes recommendations to ensure a state-of-the-art production capacity, encouraging transfers from the research community to the MyOcean team. The Scientific Advisory Committee is the reference committee to select new research investigation actions and teams through the Open Call process planned in MyOcean.

The overall management is done through and by the Executive Committee, chaired by the project manager, and composed of the 18 work-package leaders. The Executive Committee drives the overall service and development activity and is responsible for the budget / technical / timetabling objectives set by the project. The Executive Committee's main role is to implement the decisions of the governing bodies and to monitor the work. It proposes the annual work plans and budgets, and any changes required to meet project objectives within the available resources and considers reallocation of work and funding amongst tasks and partners. The Executive Committee drives the production, service and quality activities. The Project Manager - F. Adragna (Mercator Océan, France) supported by the Project Office team is in charge of the daily management of the Project. The MyOcean project management team can be contacted through myocean@mercator-ocean.fr.

\section{CONCLUSION}

Since OceanObs 1999, ocean monitoring and forecasting core services have reached a first level of maturity. A network of operational oceanography centres throughout the world has been formed: it forms a valuable capacity to provide users with a reliable depiction of the ocean based on space and in situ observations and assimilative models.

In Europe, MyOcean is undoubtedly the most important initiative for the implementation of an ocean monitoring and forecasting service. MyOcean has already played a leading role in its preparation phase in fostering European collaborations towards this objective, and will, in the coming years, be the natural framework to build the sustained Marine Core Service required for the development and sustainability of oceanography services.

MyOcean specifications rely on a thorough analysis of the stakeholders' expectations, the market demand and the science and production capacity in Europe. MyOcean is able to rely on the participation and commitments of the best ocean centres in Europe, and the involvement of experienced scientists and managers in oceanography. MyOcean is a European service opened to the rest of the world. It provides a worldwide service for ocean monitoring and forecasting which is fertilized in its science / operation / service / governance organization by international collaborations.

MyOcean has given to the European Marine Core Service its first reality: a first range of ocean monitoring and forecasting products based on ocean models and observations. Anyone can access this information, which is designed to serve adding-value downstream service providers.

This first public good service is critically dependent upon a reliable and sustained satellite and in situ observation network in oceanography.

Throughout the world, teams running ocean monitoring and forecasting core services are now facing a double challenge: their transition to an operational status to secure their service to users, and their response to new societal needs. These societal needs are now quite diverse, and are not limited to open ocean forecasts. Innovation in ocean monitoring and forecasting core services will remain an important driver for the coming years.

\section{ACKNOWLEDGEMENTS:}

This paper was written on the basis of the MyOcean description of work (660 pages), prepared by the MyOcean Board and the project manager (listed as coauthors), as well as the partners involved in the project, in particular including the 17 work package leaders: J. Dorandeu (system), P. Brasseur (research), E. Dombrowsky (global), L. Bertino (arctic), N. Kliem (baltic), J. Siddorn (atl. NWS), J. Chanut (atl. IBI), M. Tonani (mediterranean), G. Korotaev (black sea), G. Larnicol (sea level), H. Roquet (SST (Sea Surface Temperature)), R. Santoleri (color), L.-A. Breivik (ice \&wind), S. Pouliquen (In Situ), S. Keogh (service 
provision), D. Obaton (service definition) and K. Nittis (users).

The MyOcean project is co-funded by the European Commission under the FP7 space program. The preliminary design of this paper refers to past work of the European Commission marine core service implementation group, chaired by P. Ryder.

\section{REFERENCES}

1. Bahurel P. (2008): MyOcean, building up the European "Marine Core Service, in Window on GMES, first issue, May 2008, publication from the European Commission BOSS4GMES project.

2. Bell M. J, M. Lefebvre, P.-Y. Le Traon, N. Smith and K. Wilmer-Becker (2009). GODAE, The Global Ocean Data Assimilation Experiment. Oceanography Magazine, Vol. 22, No. 3, Special issue on the revolution of global ocean forecasting - GODAE: ten years of achievement.

3. Clark C. and W. Wilson (2009). An overview of global observing systems relevant to GODAE. Oceanography Magazine, Vol. 22, No. 3, Special issue on the revolution of global ocean forecasting - GODAE: ten years of achievement.

4. Desaubies, Y. (2005): Mersea, Development of a European Ocean Monitoring and Forecasting System Ocean and Marine applications for GMES. In Ocean Weather Forecasting: An Integrated View of Oceanography Edited by E. Chassignet and J. Verron, Springer.

5. Desaubies Y. (2009): Mersea, a precursor to GMES Marine Core Service. Proceedings of the 5th International Conference on EuroGOOS, 20-22 May 2008, Exeter, UK. EuroGOOS Publication, 28.

6. J.A. Johannessen, P.-Y. Le Traon, I. Robinson, K. Nittis, M. J. Bell, N. Pinardi, and P. Bahurel, 2006, Marine Environment and Security for the European Area (MERSEA) - Towards operational oceanography, American Meteorological Society, BAMS, pp. 10811090.

7. Le Traon, P.Y. J. Johannessen, I. Robinson, O. Trieschmann (2006). Report from the Working Group on Space Infrastructure for the GMES Marine Core Service. GMES Fast Track Marine Core Service Strategic Implementation Plan. Final Version, 24/04/2007.

8. Ryder P. (2007): GMES Fast Track Marine Core Service, Strategic Implementation Plan, report from the GMES Marine Core Service Implementation Group to the European Commission GMES Bureau. 